\title{
Sistema de medição ultrassônica para a determinação de propriedades físicas e acústicas de líquidos
}

\section{João G. U. Alvarez ${ }^{\star}$, Carlos A. M. Silva, Samuel S. Saraiva, Ana M. F. Fileti}

\section{Resumo}

Propriedades físico-químicas e acústicas de óleo de rícino foram estimadas para várias temperaturas por meio da técnica ultrassônica, utilizando uma célula construída no Laboratório de Engenharia de Sistemas Químicos da Faculdade de Engenharia Química da Unicamp. Foram obtidos desvios da ordem de 0,7\% para o cálculo da massa específica. Evidenciou-se que a célula ultrassônica construída e o processamento do sinal utilizado apresentaram sensibilidade para captar as variações das propriedades com a temperatura e estimar de maneira satisfatória a atenuação acústica, a velocidade do som no meio e a massa específica do óleo de rícino.

\section{Palavras-chave:}

Ultrassom, medição acústica, óleo de rícino

\section{Introdução}

As técnicas ultrassônicas são utilizadas em várias áreas da indústria química para a estimativa de propriedades físico-químicas e acústicas como a massa específica (Adamowski et al. 1993) de maneira rápida e com a possibilidade de atuar de maneira não-invasiva e não-intrusiva.

A fim de calibrar uma célula produzida por alunos do Laboratório de Engenharia de Sistemas Químicos, foram realizadas diferentes medidas ultrassônicas de óleo de rícino em um determinado intervalo de temperatura para a caracterização de propriedades do fluido, tais como: velocidade do som, massa específica e atenuação acústica. Os detalhes da geometria da célula se encontram em Silva et al. (2019).

\section{Resultados e Discussão}

Os sinais ecos capturados pelo transdutor são representados pela Figura 1 (a). O comportamento da atenuação em função da temperatura foi comparado com valores presentes na literatura e está representado na Figura 1 (b).
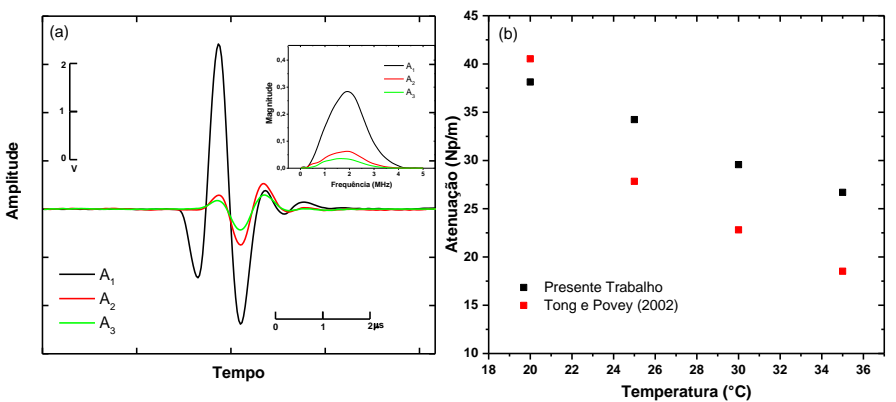

Figura 1. (a) Sinais ecos obtidos do transdutor e suas transformadas de Fourier e (b) Comparação dos resultados para a atenuação em função da temperatura

Para as medidas de massa específica, foram obtidos pequenos desvios com a literatura, como pode ser visto na Figura 2 (a). Os desvios máximos foram da ordem de $0,7 \%$.

Para a velocidade do som, o comportamento em função da temperatura se assemelhou com o encontrado na literatura com desvio máximo de $5 \%$.
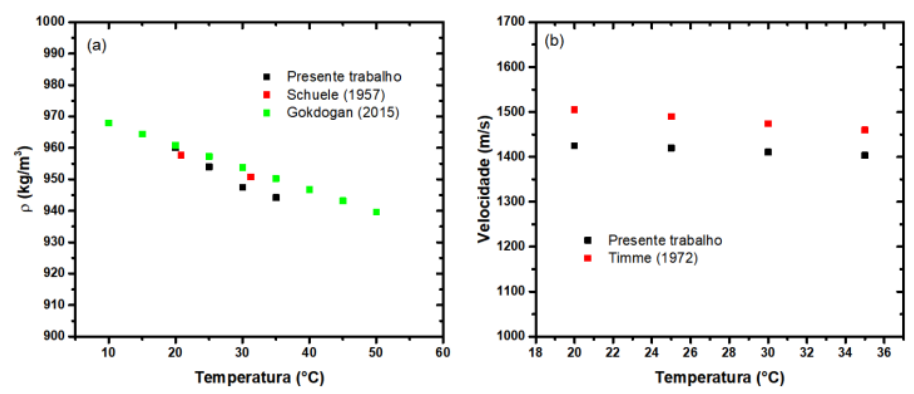

Figura 2. Comparação dos resultados obtidos para a (a) massa específica e (b) velocidade do som.

\section{Conclusões}

A célula ultrassônica construída e o processamento do sinal utilizado apresentaram sensibilidade para captar variações das propriedades com a temperatura, possibilitando estimar as propriedades físicas e acústicas do óleo de rícino.

\section{Agradecimentos}

Os autores agradecem à CAPES, PETROBRAS e à ANP pela concessão de bolsas de estudos e pelo financiamento do projeto de pesquisa.

ADAMOWSKI, J.; BUIOCHI, F.; SIMON, C.; SILVA, E.; SIGELMANN, R. Ultrasonic measurement of density of liquids. Acoustical Society of America Journal. 97. 354-361, 1995.

GOKDOGAN, O.; ERYLMAZ, T.; YESILYURT, K. M.; Thermophysical properties of castor oil (Ricinus Communis L.) biodiesel and its blends. C.T.F Cienc. Tecnol. Futuro, v. 6; n. 1, p. 95-128, 2015.

SCHUELE, D. E.; GUTOWSKI, F. A.; and CAROME E. F.; Interferometric Determination of Ultrassonic Absorption in Castor Oil, in The Journal of the Acoustical Society of America, vol. 29, 1957.

SILVA, C. A. M.; SARAIVA, S. V.; ALVAREZ, J. G. U; SILVA, F. V.; FILETI, A. M. F.; Desenvolvimento de um Sistema Supervisório para o Monitoramento em Tempo Real de Propriedades Físicas e Acústicas de Líquidos baseado em Medidas Ultrassônicas, COBISA-ISA, 2019. TIMME, R. W.; Speed of Sound in Castor Oil. Journal of The Acoustical Society of America - J ACOUST SOC AMER. 52. 10.1121/1.1913205, 1972. TONG, J. and Povey, J. W. P.; Pulse echo comparison method with FSUPER to measure velocity dispersion in $\mathrm{n}$-tetradecane in water emulsions. Ultrasonics, Volume 40, Issues 1-8, 2002, pages 37-41. 